\title{
PET of Adoptively Transferred Chimeric Antigen Receptor T Cells with ${ }^{89} \mathrm{Zr}$-Oxine
}

\author{
Michael R. Weist ${ }^{1,2}$, Renate Starr ${ }^{3}$, Brenda Aguilar ${ }^{3}$, Junie Chea ${ }^{1}$, Joshua K. Miles ${ }^{1}$, Erasmus Poku ${ }^{1}$, Ethan Gerdts ${ }^{3}$, \\ Xin Yang ${ }^{3}$, Saul J. Priceman ${ }^{3}$, Stephen J. Forman ${ }^{3}$, David Colcher ${ }^{1}$, Christine E. Brown ${ }^{3}$, and John E. Shively ${ }^{1}$ \\ ${ }^{1}$ Department of Molecular Immunology, Beckman Research Institute, City of Hope Medical Center, Duarte, California; ${ }^{2}$ Irell and \\ Manella Graduate School of Biological Sciences, City of Hope Medical Center, Duarte, California; and ${ }^{3}$ Department of Hematology, \\ City of Hope Medical Center, Duarte, California
}

Chimeric antigen receptor (CAR) T cell therapy is a promising clinical
approach for reducing tumor progression and prolonging patient
survival. However, improvements in both the safety and the potency
of CAR T cell therapy demand quantitative imaging techniques to
determine the distribution of cells after adoptive transfer. The purpose
of this study was to optimize ${ }^{89} \mathrm{Zr}$-oxine labeling of CAR T cells and
evaluate PET as a platform for imaging adoptively transferred CAR T
cells. Methods: CAR T cells were labeled with $0-1.4 \mathrm{MBq}$ of ${ }^{89} \mathrm{Zr}-$
oxine per $10^{6}$ cells and assessed for radioactivity retention, viability,
and functionality. In vivo trafficking of ${ }^{89} \mathrm{Zr}$-oxine-labeled CAR T cells
was evaluated in 2 murine xenograft tumor models: glioblastoma brain
tumors with intracranially delivered IL13Ra2-targeted CAR T cells, and
subcutaneous prostate tumors with intravenously delivered prostate
stem cell antigen (PSCA)-targeted CAR T cells. Results: CAR T cells
were efficiently labeled (75\%) and retained more than $60 \%$ of the ${ }^{89 Z \mathrm{Zr}}$
over 6 d. In vitro cytokine production, migration, and tumor cytotox-
icity, as well as in vivo antitumor activity, were not significantly reduced
when labeled with $70 \mathrm{kBq} / 10^{6}$ cells. IL13Ra2-CAR T cells delivered
intraventricularly were detectable by PET for at least $6 \mathrm{~d}$ throughout
the central nervous system and within intracranial tumors. When
intravenously administered, PSCA-CAR T cells also showed tumor
tropism, with a 9-fold greater tumor-to-muscle ratio than for CAR-
negative T cells. Conclusion: ${ }^{89} \mathrm{Zr}$-oxine can be used for labeling and
imaging CAR T cells while maintaining cell viability and function. On the
basis of these studies, we conclude that ${ }^{89} \mathrm{Zr}$-oxine is a clinically trans-
latable platform for real-time assessment of cell therapies.

Key Words: ${ }^{89} \mathrm{Zr}$-oxine; positron emission tomography; chimeric antigen receptor T cells; prostate cancer; glioblastoma

J Nucl Med 2018; 59:1531-1537

DOI: 10.2967/jnumed.117.206714

$\mathbf{T}$ he genetic modification of $\mathrm{T}$ cells to express chimeric antigen receptors (CARs), which enable these cells to specifically target and kill cancer cells, has become an important immunotherapeutic approach in the treatment of cancer (1-3). CAR T cells combine the target specificity of antibodies with the intracellular signaling components of the $\mathrm{T}$ cell receptor and costimulatory molecules to redirect $\mathrm{T}$ cell-mediated immune responses (4). Significant progress

Received Dec. 5, 2017; revision accepted Apr. 17, 2018.

For correspondence or reprints contact: John E. Shively, City of Hope Medical Center, 1500 E. Duarte Rd., Duarte, CA 91010.

E-mail: jshively@coh.org

Published online May 4, 2018.

COPYRIGHT (C) 2018 by the Society of Nuclear Medicine and Molecular Imaging. in CAR T cell therapy has been made over the past several decades, as led by the clinical success of CD19-CAR T cells against refractory B-cell malignancies, in which complete responses are achieved in most patients (5-8). Despite ongoing progress, challenges remain in improving CAR T cell therapy, including poor tumor targeting (9), normal-tissue toxicity (10), and lack of CAR T cell persistence (11). Real-time imaging to determine the dynamics of CAR T cell trafficking in both patients and animals can help address these issues. Because CAR T cells are manufactured ex vivo, they can readily be labeled for imaging before infusion. PET offers significant advantages over other imaging modalities because it is quantitative, highly sensitive, and subject to minimal tissue attenuation. Optimal nuclear imaging is achieved when the radionuclide half-life approximates the biologic action of the imaging target. Of the commercially available PET radionuclides, ${ }^{89} \mathrm{Zr}$ has a relatively long half-life $(78.4 \mathrm{~h})$ suitable for imaging CAR $\mathrm{T}$ cells over the days required for trafficking and antitumor responses.

${ }^{89} \mathrm{Zr}$-oxine has previously been used for labeling and imaging murine lymphocytes (12-15) but not human CAR T cells. ${ }^{89} \mathrm{Zr}$-oxine has preparation and functional characteristics similar to those of its SPECT counterpart, ${ }^{111}$ In-oxine, which has been used for many types of cells (16). ${ }^{111}$ In-oxine has been used to visualize the trafficking and tumor accumulation of $\gamma$ - $\delta$-T cells and HER2-primed T cells $(17,18)$. In comparison to SPECT, PET has higher resolution (19), making ${ }^{89} \mathrm{Zr}$-oxine an attractive choice for imaging cells. Another PET-based approach for labeling cells is ${ }^{18} \mathrm{~F}-\mathrm{FDG}$, which is inadequate for tracking CAR T cells because of its short half-life (109.7 min) and relatively poor radioactivity retention (20). On the basis of the existing clinical applications of ${ }^{89} \mathrm{Zr}(21)$ and its oxine complex, we selected ${ }^{89} \mathrm{Zr}$-oxine for labeling CAR T cells and imaging with PET.

We present an alternative method for labeling cells with ${ }^{89} \mathrm{Zr}$ oxine in which ${ }^{89} \mathrm{Zr}$-oxine is prepared from ${ }^{89} \mathrm{Zr}$-oxalate and retained within CAR T cells. Before cells were imaged in vivo, we identified an optimal labeling activity that maintained cell viability and function while maximizing the radioactive signal for imaging. To further assess the robustness of this PET imaging platform, we tracked ${ }^{89} \mathrm{Zr}$ oxine-labeled CAR T cells administered via 3 different delivery routes: intravenous, intratumoral, and intraventricular. These data demonstrate the tumor tropism of adoptively transferred CAR T cells and their distribution based on administration routes.

\section{MATERIALS AND METHODS}

\section{Labeling Cells with ${ }^{89} \mathrm{Zr}$-Oxine}

${ }^{89} \mathrm{Zr}$-oxalate from 3D Imaging was aliquoted into borosilicate vials. On the basis of the specific activity of aqueous ${ }^{111} \mathrm{In}$-oxine preparations (22), a $50-\mu \mathrm{L}$ quantity of $6.9 \mathrm{mM} 8$-hydroxyquinoline (oxine) in 
0.1 M 4-(2-hydroxyethyl)-1-piperazineethanesulfonic acid (HEPES) was added to each $37 \mathrm{MBq}$ of ${ }^{89} \mathrm{Zr}$-oxalate, $\mathrm{pH}$ was adjusted to 7.4 with $1 \mathrm{M}$ HEPES, and the solution was incubated at room temperature for $15 \mathrm{~min}$. After 2 washings with Hanks buffered salt solution (HBSS) (without calcium, magnesium, or phenol red), CAR T cells $\left(20 \times 10^{6} / \mathrm{mL}\right)$ were incubated with $0-1,400 \mathrm{kBq}$ of unpurified ${ }^{89} \mathrm{Zr}$ oxine solution per $10^{6}$ cells for $30 \mathrm{~min}$ at $37^{\circ} \mathrm{C}$. Past ${ }^{89} \mathrm{Zr}$ - and ${ }^{111} \mathrm{In}-$ oxine reports indicate that purification of the oxine complex is not necessary $(14,15,22)$ and that oxine is rapidly lost from labeled cells after washing (23). The radiolabeled cells were washed twice with $\mathrm{T}$ cell medium (IL15 $[0.5 \mathrm{ng} / \mathrm{mL}]$ and IL2 $[50 \mathrm{U} / \mathrm{mL}]$ ) before in vitro experiments or with HBSS plus $1 \%$ human serum albumin before in vivo experiments.

\section{Labeling Efficiency of ${ }^{89} \mathrm{Zr}$-Oxine}

The yield of the ${ }^{89} \mathrm{Zr}$-oxine synthesis was determined by instant thin-layer chromatography $(92 \% \pm 0.1 \%, n=35)$ and reversed-phase high-performance liquid chromatography (82\%) (Supplemental Fig. 1; supplemental materials are available at http://jnm.snmjournals.org). ${ }^{89} \mathrm{Zr}$-oxine remained at the origin, whereas unincorporated ${ }^{89} \mathrm{Zr} \mathrm{mi}-$ grated to the solvent front developed with $0.9 \% \mathrm{NaCl}$. A gradient of $0 \%-100 \%$ acetonitrile with $0.1 \%$ trifluoroacetic acid on a SunFire C18 column (100 ̊, $3.5 \mu \mathrm{m}, 4.6 \times 150 \mathrm{~mm}$; Waters) separated ${ }^{89} \mathrm{Zr}$-oxine complexes from unincorporated ${ }^{89} \mathrm{Zr}$. Given this high yield, the ${ }^{89} \mathrm{Zr}$ oxine solution was immediately used for cell labeling.

\section{Cell Lines}

PBT030-2 is a low-passage, patient-derived IL13R $\alpha 2$-positive tumor line derived from glioblastoma tissue that was obtained in accordance with City of Hope Institutional Review Board-approved protocols and cultured as described previously (24). To generate the PBT030-2 ffLuc-positive line for visualization with luminescence, the cells were modified by lentiviral transduction to express enhanced green fluorescent protein and firefly luciferase (ffLuc) reporter genes (24). The adherent glioblastoma cell line, U251T, was cultured as described previously (25). Prostate cancer PC3 cells (CRL-1435; ATCC) were genetically modified to express prostate stem cell antigen (PC3-PSCA) by lentiviral transduction and enriched for antigen expression by flow cytometry.

IL13R $\alpha 2$-CAR $\mathrm{T}$ cells were generated from $\mathrm{T}$ cells enriched for central memory as described by Brown et al. (1). This second-generation IL13R $\alpha 2$-CAR consists of a membrane-bound interleukin 13 (IL13) mutein with a mutation at the E13 site, an extracellular IgG4-Fc spacer containing L235E and N297Q point mutations (26), a CD4 transmembrane domain, and intracellular signaling domains of 4-1BB and $\mathrm{CD} 3 \zeta$. The lentiviral cassette also includes a truncated CD19 separated from the CAR via a T2A ribosomal skip sequence (27). The PSCA-CAR is identical to the IL13R $\alpha 2$-CAR except that the extracellular tumor-targeting domain comprises a single-chain variable fragment derived from the humanized anti-PSCA antibody clone A11 (kindly provided by Drs. Anna Wu and Robert Reiter, UCLA) (28). For CAR T cell engineering, the cells were stimulated with CD3/ CD28 Dynabeads (Invitrogen) at a ratio of 3:1 (T cell to bead) and genetically modified via lentiviral transduction. $\mathrm{T}$ cells were maintained in culture at $0.6-1 \times 10^{6}$ cells $/ \mathrm{mL}$ in X-VIVO 15 medium (Bio Whittaker) plus $10 \%$ fetal calf serum (Hyclone) and supplemented with $\mathrm{T}$ cell medium 3 times per week. Both $\mathrm{T}$ cell populations were enriched for CAR expression by selecting for the truncated CD19 component coexpressed with CAR using an anti-CD19 immunomagnetic isolation kit (Stem Cell Technologies).

\section{Cell-Labeling Efficiency and Radioactivity Retention}

Cell-labeling efficiency was determined as the percentage radioactivity in the final cell pellet over the total radioactivity added. For retention experiments, CAR $\mathrm{T}$ cells were cultured in $\mathrm{T}$ cell medium and sampled at the indicated time points. Radioactivity within the cell pellet and supernatant was assayed in a $\gamma$-counter (Packard Cobra Auto-Gamma Counter) to determine retention $(\%$ retention $=$ cell pellet radioactivity/total radioactivity $\times 100 \%$ ). For subcellular fractionation experiments, $5 \times 10^{6}$ cells were processed per the manufacturer's instructions using a subcellular fractionation kit (catalog no. 78840; ThermoFisher Scientific). Each fraction was subsequently counted for radioactivity.

\section{Assays for CAR T Cell Function}

After labeling and incubation under standard culture conditions, the cytotoxicity, cytokine production, and migration potential of labeled IL13R $\alpha 2$-CAR T cells were evaluated. For all experiments, cell viability was assessed with $0.1 \%$ propidium iodide on a MoxiFlow cassette-based flow cytometer (Orflo Technologies) before labeling, after labeling, and at the indicated time points in culture. For the nonradioactive nat $\mathrm{Zr}$-oxine preparation, $10 \mu \mathrm{L}$ of a $17 \mu \mathrm{M}^{\text {nat }} \mathrm{ZrCl}_{4}$ solution in $1 \mathrm{M}$ oxalic acid was compounded with $260 \mu \mathrm{L}$ of $6.8 \mathrm{mM}$ oxine in 0.1 M HEPES and adjusted to $\mathrm{pH} 7.4$ with $1 \mathrm{M}$ HEPES. Equivalent volumes of nat $\mathrm{Zr}$-oxine were added at specific activities toxic to CAR $\mathrm{T}$ cells $\left(1.5\right.$ and $12 \mathrm{MBq} / 10^{6}$ cells).

The cytotoxicities of ${ }^{89} \mathrm{Zr}$-oxine-labeled CAR T cells were also monitored using biophotonic luciferase assays as described by Brown et al. (25). A $5 \times 10^{4}$ PBT030-2 quantity of ffLuc-positive cells was coincubated with $5-50 \times 10^{4}{ }^{89} \mathrm{Zr}$-oxine-labeled IL13R $\alpha 2$-CAR T cells in $0.2 \mathrm{~mL}$ at the specified time points for 7 hours at $5 \% \mathrm{CO}_{2}$ and $37^{\circ} \mathrm{C}$. The plates were then supplemented with luciferin to a final concentration of $0.14 \mathrm{mg} / \mathrm{mL}$, incubated for $10 \mathrm{~min}$ in the dark, and measured for luminescence (1-s exposure) with the Victor3 plate reader (PerkinElmer). Wells with the addition of $1 \%$ sodium dodecyl sulphate were used as a reference for maximum killing, and wells without CAR T cells were used as a reference for minimum killing. For all in vitro comparisons, 2-way ANOVA was performed to determine the significance of differences between labeling conditions.

${ }^{89} \mathrm{Zr}$-oxine-labeled IL13R $\alpha 2$-CAR T cells were stimulated for $2 \mathrm{~h}$ by plate-bound IL13R $\alpha 2-F c$ (614-IR-100; R\&D Systems [0-1,000 $\mathrm{ng} /$ well]), and the secreted interferon (IFN)- $\gamma$ was quantified by an enzyme-linked immunosorbent assay (catalog no. 430108; BioLegend) per the manufacturer's instructions. Labeled and unlabeled cells were also stimulated with antigen-positive tumor cells in an in vitro stimulation assay. A $2.5 \times 10^{5}$ quantity of $\mathrm{T}$ cells was incubated overnight with $5 \times 10^{4}$ PBT030-2 ffLuc-positive cells in $0.5 \mathrm{~mL}$ of T cell medium in 24-well plates. After a 16-h incubation, the supernatants were removed, and a cytokine 10-plex human panel (catalog no. LHC0001M; ThermoFisher) was used to quantify human IFN- $\gamma$ within the supernatant, per the manufacturer's instructions.

The migration potential of ${ }^{89} \mathrm{Zr}$-oxine-labeled IL13R $\alpha 2$-CAR T cells was assessed in 96-well ChemoTx plates with a 5- $\mu \mathrm{m}$ pore diameter (catalog no. 106-5; NeuroProbe). In the lower chambers, $30 \mu \mathrm{L}$ of unconditioned Dulbecco modified Eagle medium with $2 \%$ fetal calf serum or U251T-conditioned Dulbecco modified Eagle medium with $2 \%$ fetal calf serum were added (prepared as described previously (29)). The upper chambers were loaded with $7.5 \times 10^{4} \mathrm{CAR}$ T cells/30 $\mu \mathrm{L}(2.5 \times$ $10^{6}$ cells $/ \mathrm{mL}$ ). After $4 \mathrm{~h}$ at $37^{\circ} \mathrm{C}$, residual cells were scraped off the polycarbonate filter, and the plate was centrifuged for 2 min at $400 g$. The filter was removed, and cells in the lower chamber were counted with the MoxiFlow. Percentage migration was calculated as the number of cells in the lower chamber divided by the total number of cells plated per well.

\section{Tumor Targeting of CAR T Cells}

All mouse studies were approved by the City of Hope Institutional Animal Care and Use Committee. Under anesthesia from an intraperitoneal injection of ketamine $(132 \mathrm{mg} / \mathrm{kg})$ and xylazine $(8.8 \mathrm{mg} / \mathrm{kg})$, 6- to 8-wk-old male NOD.Cg-Prkdc ${ }^{\text {scid }} I l 2 \mathrm{rg}^{\mathrm{tm} l \mathrm{Wjl} / \mathrm{SzJ}}$ (NSG) 
mice were stereotactically injected with PBT030-2 ffLuc-positive glioma cells into the left forebrain (30). A 5-mm skin incision was made along the sagittal suture, and a burr hole was drilled into the skull $2 \mathrm{~mm}$ lateral and $0.5 \mathrm{~mm}$ anterior to the bregma. A $1 \times 10^{5}$ quantity of cells in $2 \mu \mathrm{L}$ of Dulbecco modified Eagle medium/F-12 (50:50) plus B-27 and heparin supplement was injected as follows: $1 \mu \mathrm{L}$ each at depths of 2.5 and $2.25 \mathrm{~mm}$ from the dura. Eight days after tumor implantation, the mice were treated intratumorally at the tumor coordinates (i.e., intracranially) or in the right lateral ventricle (intraventricularly) with ${ }^{89} \mathrm{Zr}$-oxine-labeled $\left(70 \mathrm{kBq} / 10^{6}\right.$ cells) or unlabeled IL13R $\alpha 2-C A R$ T cells. Mice for therapy and PET studies were treated with $0.2 \times 10^{6}$ and $2.0 \times 10^{6}$ cells, respectively. Control mice with tumors were treated intratumorally with unlabeled mock-transduced $\mathrm{T}$ cells. For intratumoral injections, $\mathrm{T}$ cells in $3 \mu \mathrm{L}$ of phosphatebuffered saline were injected as follows: $0.5 \mu \mathrm{L}$ each at a depth of 3.0, $2.75,2.50,2.35,2.25$, and $2.15 \mathrm{~mm}$ from the dura. For intraventricular injections, a 5-mm skin incision was made along the sagittal suture, a burr hole drilled into the skull $0.9 \mathrm{~mm}$ lateral and $0.3 \mathrm{~mm}$ caudal to the bregma, and $\mathrm{T}$ cells in $3 \mu \mathrm{L}$ of phosphate-buffered saline were injected at a depth of $2.5 \mathrm{~mm}$ from the dura. Tumor growth was monitored and quantified by luminescence imaging on an AmiX optical imaging system and AMIView software (Spectral Instruments), and survival was assessed according to the guidelines of the American Veterinary Medical Association (30). Tukey multiple-comparison tests and log-rank tests were used to compare differences in flux

and survival, respectively. In the subcutaneous prostate PC3-PSCA tumor model, the mice were injected with $2.5 \times 10^{6}$ PC3-PSCA cells in HBSS into the right flank as described previously (28). After $28 \mathrm{~d}$, the mice were injected via the tail vein with $7.5 \times 10^{6} \mathrm{~T}$ cells $(70 \mathrm{kBq} /$ $10^{6}$ cells) or $0.37 \mathrm{MBq}$ of cell-free ${ }^{89} \mathrm{Zr}$-oxine.

\section{PET Imaging and ${ }^{89} \mathrm{Zr}$-Biodistribution Studies}

PET scans were acquired with an Inveon small-animal PET/CT system (Siemens Medical Solutions) at an energy window of 350-605 $\mathrm{keV}$ with a time resolution of $6 \mathrm{~ns}$. In the first acquisition session for the glioblastoma model, the mice remained under anesthesia from the ketamine and xylazine received before CAR T cell implantation, further supplemented by $2 \%-4 \%$ isoflurane in oxygen. At subsequent time points, $2 \%-4 \%$ isoflurane in oxygen alone was used for anesthesia. All PET scans were 10-20 min long. The data were sorted into 2-dimensional sinograms using the Fourier rebinning method and corrected for intrascan radiodecay, detector nonuniformity, and random coincidence noise. Images were reconstructed using iterative 3-dimensional ordered-subsets expectation maximization (4 iterations). CT scans were also acquired at the last imaging time point.

For biodistribution studies with ${ }^{89} \mathrm{Zr}$-oxine, major organs were removed (heart, lung, liver, spleen, stomach, large intestine, small intestine, kidneys, right quadriceps, right femur, left stifle joint, and lumbar vertebrae) after euthanasia by cardiocentesis. Brains were washed in phosphate-buffered saline and sectioned with a razor blade to separate the right and left cortices, olfactory bulbs, and cerebellum. Tissues were weighed and mea-

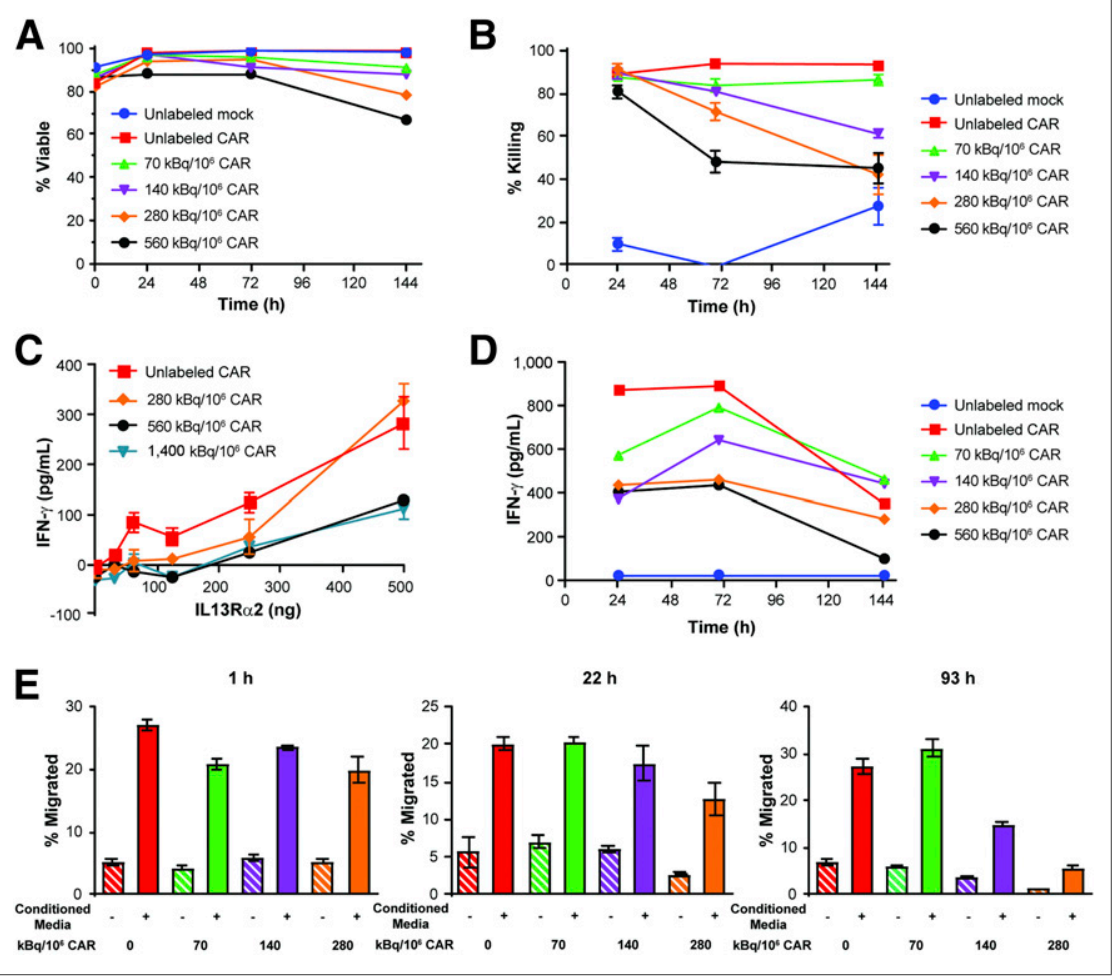

FIGURE 1. ${ }^{89} \mathrm{Zr}$-oxine does not affect cell viability or function at optimized cell labeling activity. After ${ }^{89} \mathrm{Zr}$-oxine labeling at specified specific activities, IL13Ra2-CAR T cells were cultured under standard conditions for up to $144 \mathrm{~h}$. (A) Viability of untransduced (mock) and IL13Ra2-CAR T cells was monitored over $144 \mathrm{~h}$ of cell culture. (B) IL13Ra2-CAR T cell killing of PBT030-2 ffLuc-positive cells was assessed in 7-h luciferase cytotoxicity assay at 10:1 T cell-to-tumor ratio $(n=6)$ at specified time points after ${ }^{89} \mathrm{Zr}$-oxine labeling and subsequent cell culturing. (C) Enzyme-linked immunosorbent assay for IFN-y cytokine production of ${ }^{89} \mathrm{Zr}$-oxine-labeled IL13Ra2-CAR T cells after incubation with plate-bound IL13Ra2 for $4 \mathrm{~h}(n=2)$. (D) IFN-y production determined by cytokine bead analysis of ${ }^{89} \mathrm{Zr}$-oxine-labeled IL13Ra2-CAR T cells after overnight incubation with PBT030-2 ffLuc-positive cells. (E) Migration of IL13Ra2-CAR T cells to U251T conditioned medium or control medium in 4-h Boyden chamber chemotaxis assay $(n=4)$. All data are expressed as mean \pm SE. sured for radioactivity using an automated $\gamma$-counter (Wallac Wizard 3; PerkinElmer) along with 3 dose standards. After correcting for background and radioactive decay, the percentage injected dose (\%ID) and \% ID/g of each tissue were calculated. Region-of-interest tracing of subcutaneous tumors was performed in the IRW software suite (Siemens). VivoQuant (Invicro) was used to analyze PET/CT images of the intracranial model, and the 3D Brain Atlas tool of VivoQuant was used to quantify radioactivity in the right and left cortices of the brain.

\section{Histology}

After the terminal PET imaging time point, brains or subcutaneous tumors were collected and fixed in $4 \%$ paraformaldehyde. Immunohistochemical staining for human CD3 T cells was performed on $10-\mu \mathrm{m}$-thick sections from paraffin-embedded tissue, which were deparaffinized in xylene followed by graded ethanol. The samples were then quenched in 3\% hydrogen peroxide and incubated at high $\mathrm{pH}$. The slides were washed in buffer, incubated for $30 \mathrm{~min}$ with anti-human CD3 (Dako M7254 and clone F7.2.38, 1:200) in dilution buffer, rewashed in buffer, and incubated with secondary antibody. After further washes in buffer, the slides were incubated with the chromogen diaminobenzidine tetrahydrochloride, rinsed in distilled $\mathrm{H}_{2} \mathrm{O}$, counterstained with hematoxylin, rinsed in distilled $\mathrm{H}_{2} \mathrm{O}$, rehydrated through grades of ethanol and xylene, and mounted. Adjacent slides were also stained by a standard hematoxylin and eosin technique. 


\section{RESULTS}

\section{Optimization of ${ }^{89} \mathrm{Zr}$-Oxine Labeling for CAR T Cells}

To ensure that in vivo signal was representative of cell localization, we assessed radionuclide retention and subcellular localization of ${ }^{89} \mathrm{Zr}$ after labeling. The efficiency of ${ }^{89} \mathrm{Zr}$-oxine labeling of $\mathrm{T}$ cells was $75 \% \pm 17 \%(n=33)$. By $144 \mathrm{~h}(6 \mathrm{~d})$, over $60 \%$ of the radioactivity was cell-associated (Supplemental Fig. 2A). Subcellular fractionation of the cells indicated that radioactivity was mostly cytoplasmic, which decreased over time (Supplemental Fig. 2B). These results demonstrate that ${ }^{89} \mathrm{Zr}$-oxine is retained within CAR $\mathrm{T}$ cells for an extended period.

We next determined the maximum ${ }^{89} \mathrm{Zr}$-oxine labeling specific activity that maintains CAR $\mathrm{T}$ cell viability and function. Using IL13R $\alpha 2-C A R T$ cells as a model platform, we labeled cells at specific activities of $0-1,400 \mathrm{kBq} / 10^{6}$ cells and monitored for viability and cell function over $144 \mathrm{~h}$ (6 d) (Fig. 1). Cells labeled at $70 \mathrm{kBq} / 10^{6}$ cells had the smallest decrease in viability among the activities tested (6.6\% reduction) (Fig. 1A). Because labeled CAR T cells must also kill antigen-expressing tumor cells, the cytotoxicities of ${ }^{89} \mathrm{Zr}$-oxine-labeled $\mathrm{T}$ cells were assessed with in vitro killing assays up to $145 \mathrm{~h}$ after labeling. When $\mathrm{T}$ cells were cocultured with PBT030-2 ffLuc-positive cells, CAR T cells labeled with $70 \mathrm{kBq} / 10^{6}$ cells were not significantly affected by the ${ }^{89} \mathrm{Zr}$-oxine labeling $(P=0.24)$ (Fig. 1B and Supplemental Fig. $3 \mathrm{~A})$. The chemical burden of an equivalent preparation of nat $\mathrm{Zr}$ oxine to $1,500 \mathrm{kBq} / 10^{6}$ cells did not significantly affect killing (Supplemental Fig. 3B). To test the effects of ${ }^{89} \mathrm{Zr}$-oxine labeling on antigen-dependent cytokine production, IL13R $\alpha 2-C A R T$ cells were activated with plate-bound IL13R $\alpha 2$ and evaluated for IFN- $\gamma$ production. Immediately after labeling, IFN- $\gamma$ production of cells labeled with $280 \mathrm{kBq} / 10^{6}$ cells was not significantly reduced in comparison to unlabeled cells $(P=0.06)$ (Fig. 1C). Because cells were imaged over multiple days after radiolabeling, we also evaluated cytokine production over time in an in vitro stimulation assay. After ${ }^{89} \mathrm{Zr}$-oxine labeling and culturing, samples of IL13R $\alpha 2-C A R$ T cells were incubated with PBT030-2 ffLuc-positive cells overnight, and the supernatants were analyzed for cytokine production (Fig. 1D). Production of IFN- $\gamma$ by ${ }^{89} \mathrm{Zr}$-oxine-labeled CAR T cells was unaffected at $70 \mathrm{kBq} / 10^{6}$ cells. Finally, we evaluated the chemotaxis of ${ }^{89} \mathrm{Zr}$-oxine-labeled IL13R $\alpha 2-\mathrm{CAR}$ $\mathrm{T}$ cells to U251T-conditioned medium. ${ }^{89} \mathrm{Zr}$-oxine labeling at $70 \mathrm{kBq} / 10^{6}$ cells did not significantly reduce the migration of CAR $\mathrm{T}$ cells (Fig. 1E). We observed both time- and dose-dependent effects of ${ }^{89} \mathrm{Zr}$-oxine on cell viability and function. Taken together, we identified a maximum labeling activity of $70 \mathrm{kBq} / 10^{6}$ cells for maintaining CAR T cell function over $6 \mathrm{~d}$ in vitro, and this activity was used for subsequent in vivo studies.

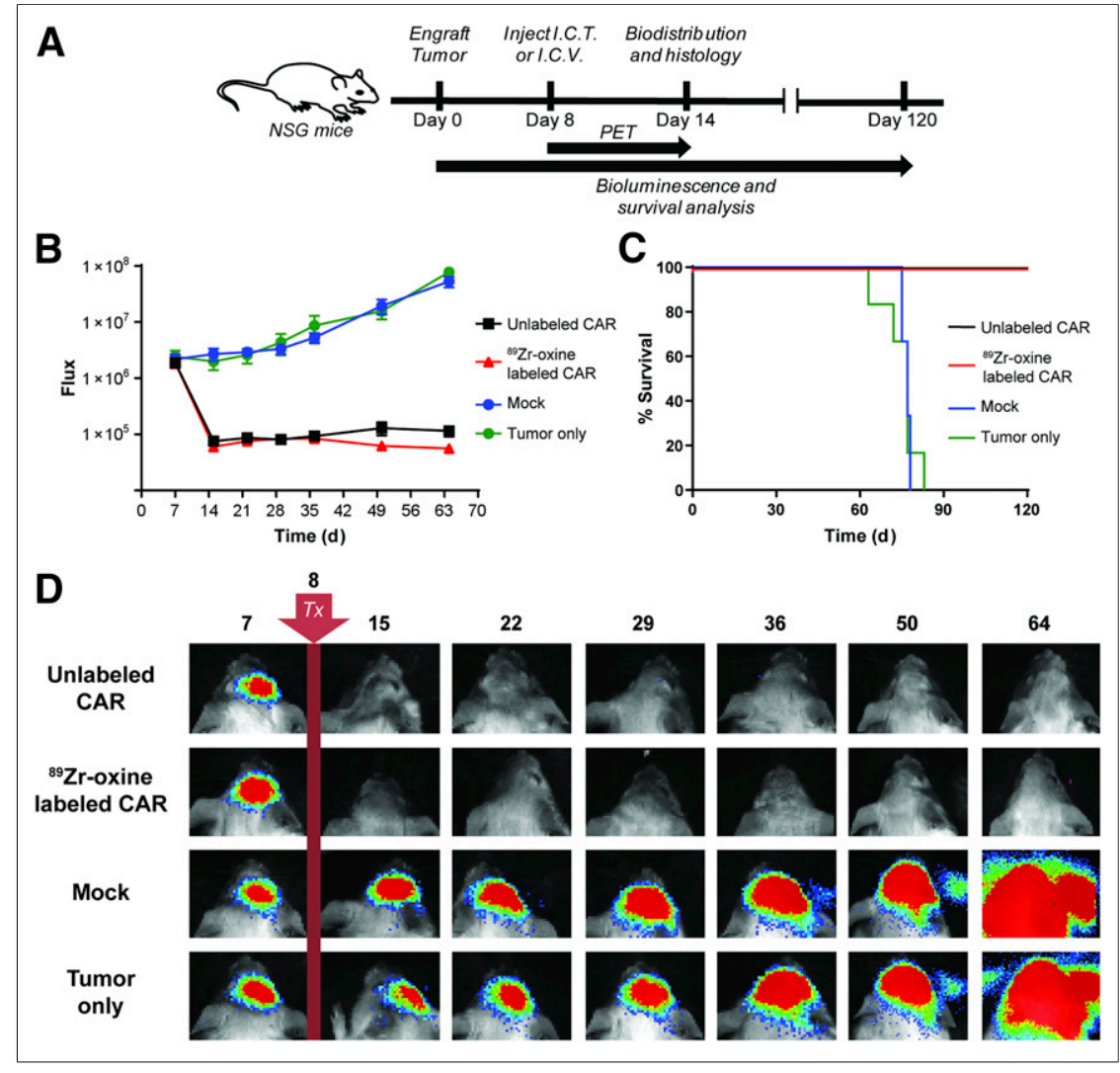

FIGURE 2. ${ }^{89} \mathrm{Zr}$-oxine-labeled IL13Ra2-CAR T cells are therapeutic in orthotopic glioma model. (A) Schema of bioluminescence and survival analysis of NSG mice engrafted with PBT030-2 glioblastoma multiforme tumors treated $(\mathrm{Tx})$ on day 8 with ${ }^{89} \mathrm{Zr}$-oxine-labeled $\left(70 \mathrm{kBq} / 10^{6} \mathrm{cells}\right)$ or unlabeled IL13Ra2-CAR T cells, or unlabeled mock T cells injected intracranially (I.C.T) or intraventricularly (I.C.V.). (B) Mean luminescence and SE of quantified tumor growth for each treatment group over $64 \mathrm{~d}\left(P=0.006\right.$ for CAR T cells [ ${ }^{89} \mathrm{Zr}$-labeled and unlabeled] vs. tumor only, $n=6)$. (C) Kaplan-Meier survival analysis of treatment groups over $120 \mathrm{~d}(P=0.0007, n=$ 6). (D) Representative bioluminescent images of each treatment group.

\section{${ }^{89} \mathrm{Zr}$-Oxine-Labeled Cells Retain Potent Antitumor Activity}

For ${ }^{89} \mathrm{Zr}$-oxine-labeled CAR $\mathrm{T}$ cells to be relevant for clinical use, the antitumor activity of the labeled cells should be comparable to that of unlabeled CAR T cells. Thus, we compared the therapeutic potential of ${ }^{89} \mathrm{Zr}$-oxine-labeled to unlabeled IL13R $\alpha 2-C A R T$ cells in an orthotopic glioblastoma tumor model with IL13R $\alpha 2$-positive PBT030-2 ffLuc-positive cells in NSG mice (Fig. 2A). We observed an equivalent reduction in tumor size for mice treated intratumorally with labeled or unlabeled IL13R $\alpha 2-C A R$ T cells, as compared with mock-transduced $\mathrm{T}$ cells or tumor only $(P=0.006$ each) over $64 \mathrm{~d}$ (Figs. $2 \mathrm{~B}$ and 2D). A similar survival benefit was also observed (Fig. 2C); mice treated with either labeled or unlabeled CAR T cells survived to the end of the study (day 120), whereas none of the mock or untreated mice survived past $83 \mathrm{~d}(P=0.0007$ each $)$.

\section{PET Imaging of ${ }^{89} \mathrm{Zr}$-Oxine-Labeled IL13Ra2-CAR T Cells After Intracranial Adoptive Transfer}

Our team is currently evaluating the locoregional delivery of IL13R $\alpha 2-C A R$ T cells in early-phase clinical trials for the treatment of glioblastoma $(1,31)$; therefore, we evaluated the utility of ${ }^{89} \mathrm{Zr}$-oxine for tracking intracranially injected CAR T cells. Cohorts of mice were imaged with PET/CT and used for ${ }^{89} \mathrm{Zr}$-biodistribution studies after CAR $\mathrm{T}$ cell administration at the tumor site or into the cerebrospinal fluid via the 
ventricular system. Independent of the presence of tumor, intraventricularly injected CAR T cells were initially localized to the cranium, including the olfactory bulbs at $0.5 \mathrm{~h}$, and then became distributed throughout the spinal column over $6 \mathrm{~d}$ (Supplemental Fig. 4A, top and middle rows). PET imaging also revealed that intraventricularly delivered CAR T cells trafficked out of the central nervous system to the liver and spleen by day 6 . By contrast, intratumorally injected CAR $\mathrm{T}$ cells remained at their injection site throughout the $6 \mathrm{~d}$ of PET imaging (Supplemental Fig. 4A, bottom row). Biodistribution studies also confirmed that radioactivity went to the spine, spleen, blood, and liver of mice injected intraventricularly, whereas most of the radioactivity remained at the injection site for intratumorally treated mice (Supplemental Figs. 4B and 4C; Supplemental Table 1). Tumor-bearing mice treated intraventricularly with ${ }^{89} \mathrm{Zr}$-oxine-labeled IL13R $\alpha 2$-CAR T cells showed a leftfrontal-cortex focus corresponding to the tumor site (Fig. 3, top row) that was not observed in mice without tumors (Fig. 3, middle row). The same anatomic area was seen in mice treated intratumorally (Fig. 3, bottom row). Because radioactivity was observed in the olfactory bulbs of mice treated intraventricularly, we affirmed that the focus corresponded to the tumor in the cortex by fitting the

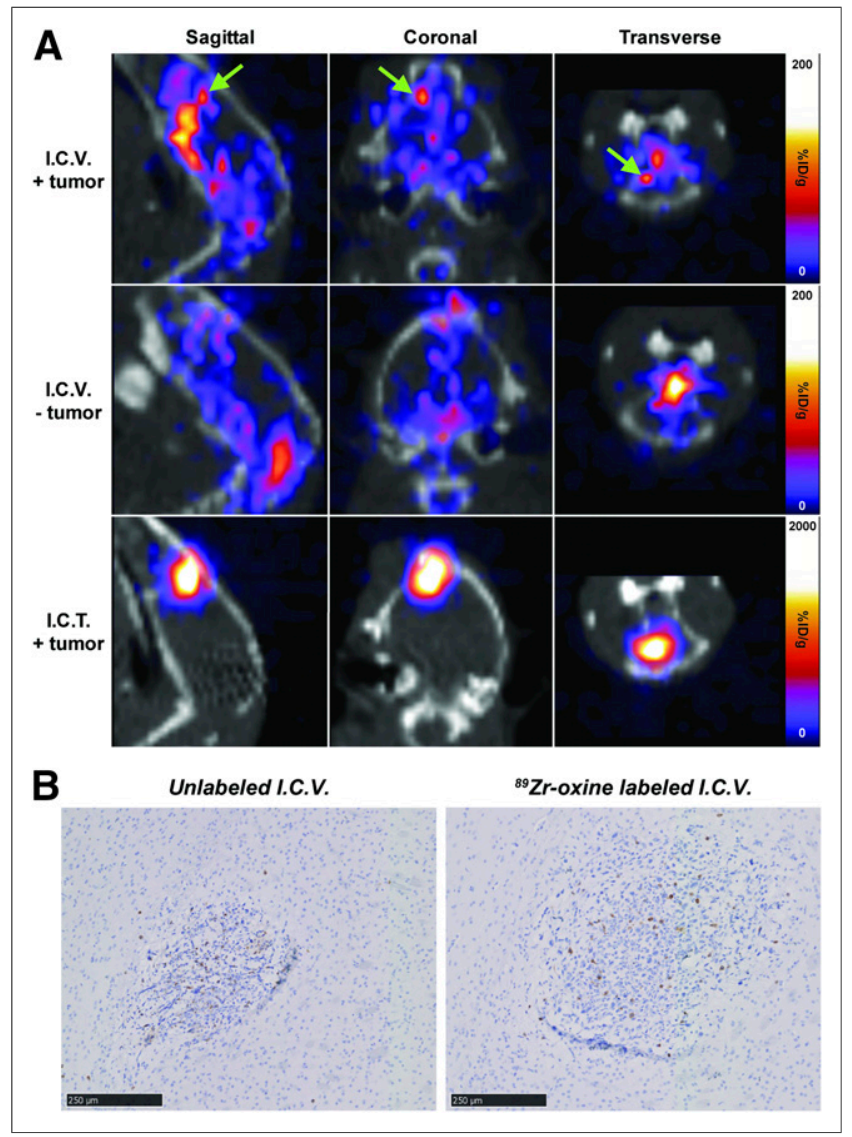

FIGURE 3. Tumor trafficking of ${ }^{89} \mathrm{Zr}$-oxine-labeled IL13Ra2-CAR T cells in brain. (A) Representative PET/CT scans of NSG mice with or without PBT030-2 ffLuc-positive tumors in left cortex at $140 \mathrm{~h}$ after treatment with ${ }^{89} \mathrm{Zr}$-oxine-labeled IL13Ra2-CAR T cells $\left(70 \mathrm{kBq} / 10^{6}\right.$ cells). In mice receiving intraventricular injections (I.C.V.), labeled CAR T cells were injected into cerebrospinal fluid via right ventricle. Intratumoral injections were administered intracranially (I.C.T.) into left cortex. Arrows represent tumor location. (B) Immunohistochemistry for human CD3 (brown) showing trafficking of I.C.V.-delivered IL13Ra2-CAR T cells to contralateral PBT030-2 ffluc-positive tumors. Scale bar is $250 \mu \mathrm{m}$.
VivoQuant 3D Brain Atlas to coregistered PET/CT scans (Supplemental Fig. 5). Tumor infiltration of human CD3 T cells, as assessed by immunohistochemistry, also confirmed the tumor trafficking of intraventricularly delivered unlabeled and ${ }^{89} \mathrm{Zr}$-oxine-labeled CAR $\mathrm{T}$ cells (Fig. 3B). By injecting the hemisphere contralateral to the tumor and measuring the radioactivity in the tumor-bearing hemisphere, we could monitor CAR T cell migration. We observed a 2-fold increase (1.01 vs. 0.51 ) in the ratio of left-hemisphere-toright-hemisphere radioactivity in tumor-bearing mice, compared with tumor-free mice (Supplemental Fig. 4C; Supplemental Table 1). Image quantification for the left and right cortices, as determined by the 3D Brain Atlas, yielded similar ratios. These data indicate that intraventricularly injected IL $13 \mathrm{R} \alpha 2$-CAR T cells traffic to contralateral tumors and become distributed throughout the central nervous system and major organ systems.

\section{PET Imaging of ${ }^{89} \mathrm{Zr}$-Oxine-Labeled PSCA-CAR T Cells After Intravenous Injection}

To further assess ${ }^{89} \mathrm{Zr}$-oxine as an imaging platform for CAR $\mathrm{T}$ cells, we evaluated the intravenous delivery of PSCA-CAR T cells in a subcutaneous prostate tumor model of PC3-PSCA cells (Fig. 4). ${ }^{89} \mathrm{Zr}$-oxine-labeled PSCA-CAR T cells, ${ }^{89} \mathrm{Zr}$-oxine-labeled untransduced $\mathrm{T}$ cells (mock), or cell-free ${ }^{89} \mathrm{Zr}$-oxine was injected into mice bearing subcutaneous PC3-PSCA xenografts and imaged over $7 \mathrm{~d}$. Radioactivity within the first $4 \mathrm{~h}$ was observed in the lungs of mice treated with $\mathrm{T}$ cells, whereas the radioactivity of the cell-free ${ }^{89} \mathrm{Zr}$ oxine was rapidly distributed throughout the blood (Fig. 4A). Over $6 \mathrm{~d}$, the signal in mice treated with ${ }^{89} \mathrm{Zr}$-oxine-labeled $\mathrm{T}$ cells shifted from the lungs to the liver and spleen whereas the signal in cell-free control mice rapidly shifted to the liver and bone (Fig. 4A; Supplemental Table 2). Radioactivity in subcutaneous tumors was detected in mice treated with CAR but not with mock $\mathrm{T}$ cells (Fig. 4C; Supplemental Table 2). PET scans revealed a steady accumulation of signal in subcutaneous tumors over $7 \mathrm{~d}$ (Fig. 4D). Tumor radioactivity was much higher in mice treated with CAR T cells $(2.44 \% \mathrm{ID} / \mathrm{g})$ than in mice treated with mock cells $(0.31 \% \mathrm{ID} / \mathrm{g})$, indicating enhanced CAR T cell trafficking to the tumor. The tumorto-blood ratios of mice treated with ${ }^{89} \mathrm{Zr}$-oxine-labeled CAR T cells was, on average, 20.0 , in comparison to 3.54 with ${ }^{89} \mathrm{Zr}$-oxinelabeled mock cells. Radioactivity was also present in tumors from the cell-free ${ }^{89} \mathrm{Zr}$-oxine control but was due to residual blood activity (Fig. 4A, bottom row); the average tumor-to-muscle ratio was greater for the CAR T cells (14.7) than for the cell-free control mice (2.59). CD3-positive cells were observed in the tumors of mice treated with ${ }^{89} \mathrm{Zr}$-oxine-labeled and unlabeled PSCA-CAR T cells but not in the mock cell-treated tumors (Fig. 4B). These data show that ${ }^{89} \mathrm{Zr}$-oxine can visualize the tumor targeting and whole-body distributions of intravenously injected CAR T cells.

\section{DISCUSSION}

One of the primary goals of this study was to provide proof-ofprinciple data for a clinical imaging platform using ${ }^{89} \mathrm{Zr}$-oxine to track CAR $\mathrm{T}$ cells after adoptive transfer in patients. Our team has a longstanding interest in the locoregional delivery of CAR $\mathrm{T}$ cells for the treatment of brain tumors and other solid tumors $(1,24,27,28,31)$. In our ongoing clinical trial (NCT02208362), we are evaluating the safety and antitumor effects of up to $200 \times 10^{6}$ IL13R $\alpha 2-C A R T$ cells for the treatment of recurrent glioblastoma via intratumoral and intraventricular routes of administration. We recently reported a case study involving a patient with recurrent 


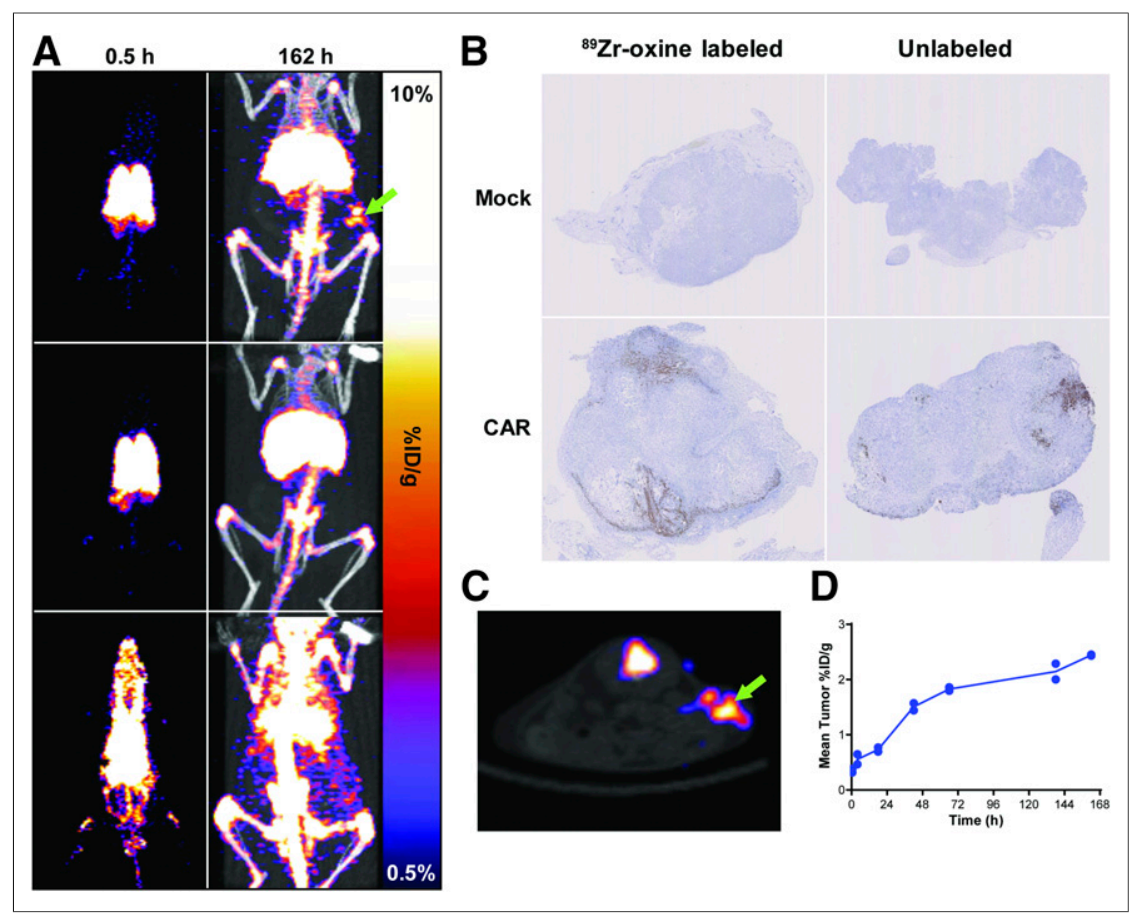

FIGURE 4. Visualizing in vivo tumor targeting of ${ }^{89} \mathrm{Zr}$-oxine-labeled PSCA-CAR T cells. (A) Representative PET (left) and PET/CT (right) maximum-intensity projections at 0.5 and $162 \mathrm{~h}$, respectively. NSG mice with PC3-PSCA tumors in right flank (arrow) were intravenously treated with ${ }^{89} \mathrm{Zr}$-oxine PSCA-CAR T cells (top row), ${ }^{89} \mathrm{Zr}$-oxine-labeled mock-transfected T cells (middle row), or ${ }^{89} \mathrm{Zr}$-oxine alone (bottom row). (B) Antihuman CD3 (brown) immunostaining for T cells in tumors of labeled or unlabeled mock or PSCA-CAR T cells. (C) Axial section showing PET signal of ${ }^{89} \mathrm{Zr}$-oxine PSCA-CAR T cells at subcutaneous tumor (arrow) of representative mouse at $162 \mathrm{~h}$. (D) Quantification of PET images in subcutaneous tumors of mice treated with ${ }^{89} \mathrm{Zr}$-oxine PSCA-CAR T cells over $7 \mathrm{~d}$. labeling at $70 \mathrm{kBq} / 10^{6}$ cells did not affect CAR $\mathrm{T}$ cell in vitro function or antitumor efficacy. The toxicity of higher radioactive doses on cell viability and function was not due to chemical burden and did not present until several days after labeling. Previously published studies also used ${ }^{89} \mathrm{Zr}$-oxine at specific activities of $32-334 \mathrm{kBq} / 10^{6} \mathrm{mu}-$ rine bone marrow and CD8-positive $\mathrm{T}$ cells $(14,15)$, an activity range that approximates the optimal $70 \mathrm{kBq} / 10^{6}$ human CAR T cells determined in our study. These studies provide evidence that the tracking of ${ }^{89} \mathrm{Zr}$ oxine-labeled cells by PET imaging is representative of their unlabeled counterparts.

We also visualized the trafficking of intravenous ${ }^{89} \mathrm{Zr}$-oxine-labeled PSCA-CAR T cells to subcutaneous tumors with PET imaging, demonstrating the utility of this platform for tracking systemically delivered cells. As a control, we found that intravenously injected ${ }^{89} \mathrm{Zr}$-oxine rapidly bound serum proteins and was mostly bone- and liverassociated after $6 \mathrm{~d}$. This bone-seeking phenomenon is similar to that reported previously for weakly chelated ${ }^{89} \mathrm{Zr}$ (33). It follows that ${ }^{89} \mathrm{Zr}$ lost from cells because of death or efflux can be estimated from the activity of the bone. In a previous study, Sato et al. (14) showed tumor trafficking and therapy of intravenous ${ }^{89} \mathrm{Zr}$-oxine-labeled CD8-positive $\mathrm{T}$ cells to subcutaneous tumors; however, $\mathrm{T}$ cells in the tumor were multifocal glioblastoma multiforme who received multiple infusions of IL13R $\alpha 2$-CAR T cells delivered first intratumorally after tumor resection and then intraventricularly to the cerebral spinal fluid. Although intratumoral therapy appeared to control local tumor recurrence, complete elimination of multifocal tumors, including lesions in the spine, was observed only after intraventricular delivery. The presented data further suggest that intraventricular but not intratumoral delivery yields cell distributions capable of surveying the central nervous system. When labeling the clinical product at 70 $\mathrm{kBq} / 10^{6}$ cells for imaging, we expect doses of up to $14 \mathrm{MBq}$ per intracranial infusion. Although $40 \%$ less than intravenous ${ }^{89} \mathrm{Zr}$ antibodies (32), the smaller volume of distribution within the cerebral spinal fluid should yield comparable activities per unit volume. This experience highlights the importance of methods, such as ${ }^{89} \mathrm{Zr}$ oxine cell imaging, that enable the tracking of adoptively transferred CAR T cells for optimizing routes of delivery and dosing schedules.

We demonstrated that human CAR T cells can be labeled and imaged with ${ }^{89} \mathrm{Zr}$-oxine. The successful labeling of CAR T cells was in part achieved by generating ${ }^{89} \mathrm{Zr}$-oxine from ${ }^{89} \mathrm{Zr}$-oxalate at a reproducibly high efficiency without further purification. Previously reported methods for generating ${ }^{89} \mathrm{Zr}$-oxine have required extraction with chloroform $(12,13)$ or conversion to ${ }^{89} \mathrm{ZrCl}_{4}$ and addition of polysorbate-80 $(14,15)$, which was excluded to avoid any unanticipated cell toxicity and only marginally increases the radiolabeling efficiency (92\%-97\%). Cell labeling with ${ }^{89} \mathrm{Zr}$-oxine was more efficient than with the previous methods ( $75 \%$ vs. $44 \%$ (14) or $61 \%$ (13)), possibly because of the cell type or the higher cell concentration used in our labeling. Importantly, we showed that ${ }^{89} \mathrm{Zr}$-oxine not confirmed, and ${ }^{89} \mathrm{Zr}$-oxine-labeled cell therapy was not compared with an unlabeled control. A small percentage of our PSCA-CAR T cell dose accumulated in tumors over $7 \mathrm{~d}(0.48 \%$ and $0.70 \%)$, which is equivalent to 37,000 and 54,000 cells of the initial cell dose. This finding could be due to a limited number of cells reaching arterial circulation because of pulmonary entrapment (34), inadequate levels of chemotactic stimuli and adhesion molecules (35), or downregulation of the tumor antigen (36). By visualizing and quantifying cell uptake, future studies will investigate the properties of CAR T cells and tumors that affect optimal tumor trafficking and infiltration.

An inherent limitation of ${ }^{89} \mathrm{Zr}$-oxine or other ex vivo labeling methods is that the measured signal reflects the number of injected cells and does not account for cell division or death. For instance, a minority of injected cells may proliferate and initiate the majority of the antitumor response (37), and ${ }^{89} \mathrm{Zr}$-oxine would detect only the preliminary migration. Modifying CAR T cells with reporter genes would account for proliferation after injection; in fact, our IL13R $\alpha 2-C A R T$ cells have been modified to express herpes simplex virus type 1 thymidine kinase and imaged with PET in patients (38). This approach enables longitudinal imaging if transfected cells are present but is limited by reduced specificity, an additional ex vivo transfection, and potential immunogenicity. If both imaging strategies are used, improvements in CAR T cell therapy can be evaluated, such as enhanced ex vivo expansion methods (39), cell engineering (40), or tumor invasion (41). Thus, both ${ }^{89} \mathrm{Zr}$-oxine cell labeling and reporter genes are complementary methods for evaluating the percentage of injected dose and the total number of effector cells at a given time within tumors, respectively. 


\section{CONCLUSION}

${ }^{89} \mathrm{Zr}$-oxine was generated using a rapid, biocompatible method that efficiently labeled CAR T cells with minimal loss of viability or function at the optimal specific activity of $70 \mathrm{kBq} / 10^{6}$ cells. Preclinically, this method can be used to optimize the tumor targeting of different CAR T cell therapies, such as those with newly engineered CARs, tumor models, or routes of injection. This method can also be used to evaluate the effect of immunomodulatory compounds or radiation therapy on the migration of ${ }^{89} \mathrm{Zr}$-oxine-labeled cells. Because both ${ }^{89} \mathrm{Zr}$ and oxine formulations are already used for clinical imaging, ${ }^{89} \mathrm{Zr}$-oxine labeling should have immediate clinical utility for evaluating the dynamics of CAR T cell trafficking. This information would provide realtime evaluation of cell therapy, offering clinicians the opportunity to intervene or continue therapy if tumor targeting is observed.

\section{DISCLOSURE}

Research reported in this publication was supported by the National Cancer Institute of the National Institutes of Health under awards P30CA033572 and R01FD005129, the Prostate Cancer Foundation Challenge Award, Gateway for Cancer Research (G-14-600), and the California Institute for Regenerative Medicine (CIRM; TR3-05641). No other potential conflict of interest relevant to this article was reported. The content is solely the responsibility of the authors and does not necessarily represent the official views of the National Institutes of Health.

\section{REFERENCES}

1. Brown CE, Alizadeh D, Starr R, et al. Regression of glioblastoma after chimeric antigen receptor T-cell therapy. N Engl J Med. 2016;375:2561-2569.

2. Priceman SJ, Forman SJ, Brown CE. Smart CARs engineered for cancer immunotherapy. Curr Opin Oncol. 2015;27:466-474.

3. Debinski W, Gibo DM, Hulet SW, Connor JR, Gillespie GY. Receptor for interleukin 13 is a marker and therapeutic target for human high-grade gliomas. Clin Cancer Res. 1999;5:985-990.

4. Thomas C, Tampe R. Proofreading of peptide-MHC complexes through dynamic multivalent interactions. Front Immunol. 2017;8:65.

5. Maus MV, Grupp SA, Porter DL, June CH. Antibody-modified T cells: CARs take the front seat for hematologic malignancies. Blood. 2014;123:2625-2635.

6. Ramos CA, Savoldo B, Dotti G. CD19-CAR trials. Cancer J. 2014;20:112-118.

7. Batlevi CL, Matsuki E, Brentjens RJ, Younes A. Novel immunotherapies in lymphoid malignancies. Nat Rev Clin Oncol. 2016;13:25-40.

8. Gross G, Waks T, Eshhar Z. Expression of immunoglobulin-T-cell receptor chimeric molecules as functional receptors with antibody-type specificity. Proc Natl Acad Sci USA. 1989;86:10024-10028.

9. Kakarla S, Gottschalk S. CAR T cells for solid tumors: armed and ready to go? Cancer J. 2014;20:151-155.

10. Bonifant CL, Jackson HJ, Brentjens RJ, Curran KJ. Toxicity and management in CAR T-cell therapy. Mol Ther Oncolytics. 2016;3:16011.

11. Sadelain M, Brentjens R, Riviere I. The promise and potential pitfalls of chimeric antigen receptors. Curr Opin Immunol. 2009;21:215-223.

12. Ferris TJ, Charoenphun P, Meszaros LK, Mullen GE, Blower PJ, Went MJ. Synthesis and characterisation of zirconium complexes for cell tracking with Zr-89 by positron emission tomography. Dalton Trans. 2014;43:14851-14857.

13. Charoenphun P, Meszaros LK, Chuamsaamarkkee K, et al. [ $\left.{ }^{89} \mathrm{Zr}\right]$ oxinate4 for long-term in vivo cell tracking by positron emission tomography. Eur J Nucl Med Mol Imaging. 2015;42:278-287.

14. Sato N, Wu H, Asiedu KO, Szajek LP, Griffiths GL, Choyke PL. ${ }^{89} \mathrm{Zr}$-oxine complex PET cell imaging in monitoring cell-based therapies. Radiology. 2015; 275:490-500.

15. Asiedu KO, Koyasu S, Szajek LP, Choyke PL, Sato N. Bone marrow cell trafficking analyzed by ${ }^{89} \mathrm{Zr}$-oxine positron emission tomography in a murine transplantation model. Clin Cancer Res. 2017;23:2759-2768.
16. Roca M, de Vries EF, Jamar F, Israel O, Signore A. Guidelines for the labelling of leucocytes with ${ }^{111}$ In-oxine: Inflammation/Infection Taskgroup of the European Association of Nuclear Medicine. Eur J Nucl Med Mol Imaging. 2010;37:835841.

17. Stanton SE, Disis ML. Clinical significance of tumor-infiltrating lymphocytes in breast cancer. $J$ Immunother Cancer. 2016;4:59.

18. Nicol AJ, Tazbirkova A, Nieda M. Comparison of clinical and immunological effects of intravenous and intradermal administration of alpha-galactosylceramide (KRN7000)-pulsed dendritic cells. Clin Cancer Res. 2011;17:5140-5151.

19. Livieratos L. Technical pitfalls and limitations of SPECT/CT. Semin Nucl Med. 2015;45:530-540.

20. Botti C, Negri DR, Seregni E, et al. Comparison of three different methods for radiolabelling human activated T lymphocytes. Eur J Nucl Med. 1997;24:497-504.

21. Jauw YW, Menke-van der Houven van Oordt CW, Hoekstra OS, et al. Immunopositron emission tomography with zirconium-89-labeled monoclonal antibodies in oncology: what can we learn from initial clinical trials? Front Pharmacol. 2016;7:131

22. Kelly JD, inventor; GE Healthcare Ltd., assignee. Indium-111 oxine complex composition. U.S. patent US4335095. June 15, 1982.

23. Thakur ML, Segal AW, Louis L, Welch MJ, Hopkins J, Peters TJ. Indium-111labeled cellular blood components: mechanism of labeling and intracellular location in human neutrophils. J Nucl Med. 1977;18:1022-1026.

24. Brown CE, Starr R, Martinez C, et al. Recognition and killing of brain tumor stem-like initiating cells by CD8 + cytolytic T cells. Cancer Res. 2009;69:88868893.

25. Brown CE, Wright CL, Naranjo A, et al. Biophotonic cytotoxicity assay for highthroughput screening of cytolytic killing. J Immunol Methods. 2005;297:39-52.

26. Jonnalagadda M, Mardiros A, Urak R, et al. Chimeric antigen receptors with mutated IgG4 Fc spacer avoid fc receptor binding and improve $\mathrm{T}$ cell persistence and antitumor efficacy. Mol Ther. 2015;23:757-768.

27. Hong H, Brown CE, Ostberg JR, et al. L1 cell adhesion molecule-specific chimeric antigen receptor-redirected human $\mathrm{T}$ cells exhibit specific and efficient antitumor activity against human ovarian cancer in mice. PLoS One. 2016;11: e0146885.

28. Priceman SJ, Gerdts EA, Tilakawardane D, et al. Co-stimulatory signaling determines tumor antigen sensitivity and persistence of CAR $\mathrm{T}$ cells targeting PSCA+ metastatic prostate cancer. Oncoimmunology. 2017;7:e1380764.

29. Brown CE, Vishwanath RP, Aguilar B, et al. Tumor-derived chemokine MCP1/CCL2 is sufficient for mediating tumor tropism of adoptively transferred T cells. J Immunol. 2007;179:3332-3341.

30. Kahlon KS, Brown C, Cooper LJ, Raubitschek A, Forman SJ, Jensen MC. Specific recognition and killing of glioblastoma multiforme by interleukin 13zetakine redirected cytolytic T cells. Cancer Res. 2004;64:9160-9166.

31. Brown CE, Badie B, Barish ME, et al. Bioactivity and safety of IL13Ralpha2redirected chimeric antigen receptor $\mathrm{CD} 8+\mathrm{T}$ cells in patients with recurrent glioblastoma. Clin Cancer Res. 2015;21:4062-4072.

32. Deri MA, Zeglis BM, Francesconi LC, Lewis JS. PET imaging with ${ }^{89} \mathrm{Zr}$ : from radiochemistry to the clinic. Nucl Med Biol. 2013;40:3-14.

33. Abou DS, Ku T, Smith-Jones PM. In vivo biodistribution and accumulation of ${ }^{89} \mathrm{Zr}$ in mice. Nucl Med Biol. 2011;38:675-681.

34. Fischer UM, Harting MT, Jimenez F, et al. Pulmonary passage is a major obstacle for intravenous stem cell delivery: the pulmonary first-pass effect. Stem Cells Dev. 2009;18:683-692.

35. Slaney CY, Kershaw MH, Darcy PK. Trafficking of T cells into tumors. Cancer Res. 2014;74:7168-7174

36. Gardner R, Wu D, Cherian S, et al. Acquisition of a CD19-negative myeloid phenotype allows immune escape of MLL-rearranged B-ALL from CD19 CART-cell therapy. Blood. 2016;127:2406-2410.

37. Sathaliyawala T, Kubota M, Yudanin N, et al. Distribution and compartmentalization of human circulating and tissue-resident memory $\mathrm{T}$ cell subsets. Immunity. 2013;38:187-197.

38. Keu KV, Witney TH, Yaghoubi S, et al. Reporter gene imaging of targeted T cell immunotherapy in recurrent glioma. Sci Transl Med. 2017;9:eaag2196.

39. Song GY, Hong L, Zhang H, Zhang J, Li Y, Feng H. Clinical outcomes of combined lateral extra-articular tenodesis and intra-articular anterior cruciate ligament reconstruction in addressing high-grade pivot-shift phenomenon. Arthroscopy. 2016;32:898-905.

40. Jackson HJ, Rafiq S, Brentjens RJ. Driving CAR T-cells forward. Nat Rev Clin Oncol. 2016;13:370-383.

41. Scarfò I, Maus MV. Current approaches to increase CAR T cell potency in solid tumors: targeting the tumor microenvironment. J Immunother Cancer. 2017;5:28. 